\title{
Medicamentos: 0 bOM Senso na balança
}

Entendo como bastante estimulante, sem intenção de trocadilho, o fato de começarem a surgir publicações interessadas em avaliar as condições relacionadas ao uso de drogas habitualmente prescritas, em qualquer faixa etária, mas principalmente naqueles com maior potencial de repercussões fisiológicas nocivas, como os idosos e crianças.

O uso de medicações psicoativas ocupa um lugar especial neste tema, visto que os alvos centrais destas substâncias podem ser vários, trazendo maior chance de provocarem efeitos colaterais.

No dia-a-dia da clínica, não raro os sintomas mais sutis são deixados de lado e subvalorizados pelos médicos, uma vez que as condições de saúde dos idosos trazem grandes preocupações e, com isso, queixas como engasgos leves, boca seca, diminuição do paladar, formação de aftas, disfonia, tosse crônica e cáries parecem secundários quando comparados aos grandes quadros de alteração de humor, de inadequação sociocomunicativa ou de sintomas psicóticos.

O artigo "Fluxo salivar e uso de drogas psicoativas em idosos" conduz um estudo pormenorizado e bem elaborado da distribuição do uso de drogas em um grupo restrito de sujeitos pertencendo à terceira idade, e compara o fluxo de saliva com um grupo de sujeitos da mesma idade que não ingere substâncias psicoativas.

Embora entendamos que uma estratificação por grupo de drogas seja um passo importante para termos uma melhor compreensão das repercussões de drogas de efeito central na qualidade de vida desta população, os resultados são claros e indicam o potencial nocivo que estas drogas possuem isoladamente, e provavelmente ainda mais quando associadas com outras que são habitualmente prescritas conjuntamente para idosos, como diuréticos e betabloqueadores, entre outros.

Henrique Olival Costa

Referência

Cabrera MAS, Mesas AE, Rossato LA, Andrade SM. Fluxo salivar e uso de drogas psicoativas em idosos. Rev Assoc Med Bras 2007; 53 (2): 178-81. 